\title{
Myth and Antinomy in Early Childhood Education: Formal vs. Applied Curricula and Professional Development ${ }^{*}$
}

\author{
Domna-Mika Kakana, Anastasia Mavidou \\ University of Thessaly, Volos, Greece
}

\begin{abstract}
Kindergarten is considered as the first significant educational context that children interface. As a result, it is very interesting to understand the type of learning that they interface in such context. The present study attempts to delineate the actual educational practices that teachers apply, as well as the instructional content that children are taught. To this aim, 77 teachers and a total of 187 pre-designed activities were recorded in systematic observation by trained staff, who were familiarized prior to the research with the observational scale. The analysis of the data uncovered several specific codes, namely, the selected themes that teachers developed, time sequence and repeatability, theme selection criteria, content of educational activities (concerning the learning areas, the exact activities that occurred, the educational material teachers used, and the space of classroom that activities were conducted), and teaching methods. The results indicated that there are considerable similarities among the practices that teachers apply, regardless of the theme or the class of children. More specifically, teachers tended to develop repeatedly specific themes every year without any significant adjustments. Moreover, they emphasized on language education, as they included it in each and every theme they taught, while mathematics and other learning areas (e.g., new technologies, physical education, etc.) were surprisingly contemned. Kindergarten teachers seem to preserve a model of practice that is repeated in every theme development. Such a model includes lecturing the whole class and individual consolidation activities. The model of teaching that emerged from our analysis illustrated that the teacher-centered approach prevails, while teachers' practice is defined by old-fashioned ways. As a consequence, our results show that further investigation should be conducted in order to earn deeper insight on the reasons that lead teachers to conserve this kind of teaching practices and select the instructional content.
\end{abstract}

Keywords: instructional content, teaching practices, kindergarten, teaching methods, theme development

\section{Introduction}

The importance of preschool education is widely recognized not only for its essentiality in children's development, but also for its impact on the students' achievements during the following school years. The constantly increasing interest in preschool education proves its vital role in social, emotional, cognitive, and physical growth of children (Melhuish, 2011). Additionally, high quality of preschool education establishes more long-term assets for students (Allen, 2011; Giardiello, McNulty, \& Anderson, 2013). Therefore, the combination of high quality and long-lasting preschool education facilitates the best results for young children

\footnotetext{
*Acknowledgments: The authors wish to acknowledge the valuable contributions of the kindergarten teachers who accepted to participate in the current study, as well as those who helped selflessly to conduct the survey.

Domna-Mika Kakana, Ph.D., professor, Faculty of Preschool Education, University of Thessaly.

Anastasia Mavidou, ,M.Sc., researcher, Laboratory of Theoretical and Applied Pedagogy, University of Thessaly.
} 
(Organization for Economic Co-operation and Development [OECD] Reports, 2004).

Nevertheless, the quality of preschool education is reflected on the curricula that are utilized by each country. There are two wide categories of types of curricula that occur universally (Flouris, 1995; Ntoliopoulou, 2005): (a) content-centered, where the focus is on the acquisition and memorization of information; and (b) child-centered programs that address children's needs and interests and construct knowledge through immediate experiences.

According to the OECD $(2001 ; 2003)$, several approaches are applicable to preschool education. For instance, many countries focus mostly on academic development and view kindergarten as a preparation stage before formal school starts, while others (mainly in Scandinavian and central Europe) emphasize on the socio-emotional development of preschoolers. Regardless of the followed pattern, kindergarten curricula demonstrate higher levels of flexibility than the curricula of other grades. However, the educational content remains quite vague and kindergarten teachers have to select and tailor it according to their class.

\section{Teachers' Perceptions}

The content that teachers decide to teach reflect the socially transmitted perceptions of what is feasible and important for the specific age of children (New, 1999). Therefore, teachers' perceptions are vital to their instructional choices in the class.

Spodek (1988) argued that there are two broad categories of theories that teachers hold: (a) explicit; and (b) implicit. The former refers to those theories that are formally expressed in educating courses of pre-service teachers, as well as in literature. On the other hand, implicit theories concern ideas about instruction that are influenced by personal experiences and practical knowledge of teachers. These theories are essential for instructional decisions that occur in a classroom environment.

Therefore, Spodek's (1988) classification offers a sufficient explanation to the gap that exists between formal and applied curricula. Both in- and pre- service teachers seem to have developmentally appropriate theories about instruction, while their practice tends to be aligned with old-fashioned methods, such as knowledge-centered instruction and emphasis on results of learning (Charlesworth, Hart, Burts, \& Hernandez, 1991; Leung, 2012; Rentzou \& Sakellariou, 2011). Developmentally appropriate practices are widely accepted by curricula, formal university institutes, and literature, which may impede teachers to declare their rejection about this theory of learning (Rentzou \& Sakellariou, 2011).

Apparently, there is disparity between the formally expressed ideas about instruction and everyday practice of teachers. Since the formal curricula and the developmentally appropriate practices are well known, the research about instructional content contributes to get insight about the real experiences that children have in kindergarten classrooms and, thus, highlights the process that children develop socially, emotionally, and cognitively (Kallestad \& Ødegaard, 2013).

\section{Instructional Content}

Both learning and developmental theories highlight the significance of content in the learning process, as the level of its difficulty impacts the achievements of the educated children (Claessens, Engel, \& Curran, 2014). Specifically, their exposure to a basic level of content in mathematics, such as counting to 10 and recognizing geometrical shapes, seems to be related with low performance in mathematics (Bodovski \& Farkas, 2007; Engel, Claessens, \& Finch, 2013). According to Claessens et al. (2014), the advanced level of content in mathematics is considered the addition and subtraction, the comprehension of quantities of numbers, and 
classification processes. Regarding the language, the recognition of letters, writing of letters, and writing of the name are considered as basic content, while the instruction of phonological awareness, silent and reading out loud, and comprehension of text are categorized as advanced content.

Unfortunately, kindergarten teachers dedicate much more time in basic content than in advanced, even though it is proven that advanced content impacts positively children's achievement (Claessens et al., 2014), which is aligned with the zone of proximal development that Vygotsky (1978) has established.

Previous research in the instructional content applied in kindergarten classrooms showed that teachers emphasized on the preparation for the elementary grade (Spodek, 1988). The program which they strictly followed every day contained reading and writing activities, story narrations, instruction of the whole class through direct teaching, as it was considered the most appropriate by teachers, and individual work sheets (Hatch \& Freeman, 1988).

On the contrary, in Norway, preschool children work mostly in small groups with activities that emerge from their initiative. The pre-designed activities cover only $20 \%$ of the total instructional time and are directly related with a learning area, such as language, art, and creativity (Kallestad \& Ødegaard, 2013).

Nevertheless, limited evidence exists concerning the applied practices and the exact instructional content that is taught in kindergarten. As a result, the present study was designed in order to enlighten those educational practices. More specifically, the main goal of this study is the investigation of the instructional content that teachers apply in Greek kindergarten classes (i.e., the chosen topics and the selection criteria, the development of activities and the methodology they follow, as well as educational material).

The present study is based on the previous research of Kakana (2011), which indicated that instructional content in kindergarten is applied in a limited range that follows seasonal sequences. In addition, although current curricula in Greece are aligned with developmentally appropriate practices, their implementation seems to puzzle teachers, as their everyday practices, including the topics, the way they develop them, and the instructional activities, are mainly knowledge-centered and old-fashioned. Meanwhile, the topics are mainly related to general encyclopedia knowledge and not to current social and environmental issues from students' everyday life in the 21st century (Kakana, 2011). Although a new curriculum is published and proposed for kindergarten teachers since 2011, which includes clear methodological suggestions, topics, and instructional content that is aligned with current curriculums worldwide (Tickell, 2011), we expected that present findings would be consistent with Kakana's (2011) research. More specifically, we hypothesized that kindergarten teachers' practices would be stereotypic and traditional, as well as teacher-centered, regardless of the class, the theme they developed, and the academic year they occurred.

\section{Method}

\section{Participants/Sample}

The participating schools in this study were 57 kindergartens from the wide region of the city of Volos (Greece), which corresponds to 77 teachers and a total number of 187 pre-designed activities.

\section{Data Collection Instrument}

The application of the pre-designed activities was documented through an observation scale, which was developed and applied in the previous research (Kakana, 2011).

The observation scale consisted of two parts. The first one included information that teachers declared after a brief conversation related to the topics and the selection criteria (e.g., "Ask the teacher about the theme 
he/she selected, what are his/her selection criteria, what are the educational goals, and from what cognitive areas they stem from?"). The second part acquired information which stemmed from systematic observation of instruction and contained questions that focused on chosen topics and the exact content of instruction (e.g., "Describe the exact content of an activity, what time did it start, and where?" "How were children introduced to the theme?" and "How the activity ended?"), the methods teachers employed (e.g., "What instructional methods the teacher used?"), and educational materials they used (e.g., "Report and describe the instructional materials [visual or audio forms] which were used for the needs of the activity").

\section{Procedure}

Trained observers in systematic observation, who had been familiarized before the research with the observational scale, selected the data. Every classroom hosted three observers who were asked to document one or two re-designed activities. Every observer filled an individual scale, which was triangulated with each other with a consistency level of $95 \%$. In case that the consistency was lower than the limit set, only the scale with the most detailed documentation was accepted.

The process of documentation was held in two consecutive academic years (2012-2013 and 2013-2014). Specifically, the selection of data in both academic years was carried out during the month of November $(11 / 14 / 2012,11 / 21 / 2012,11 / 19 / 2013$, and 11/26/2013), in order to control the repeatability and seasonal sequence of the topics. In total, every class was observed from at least one time to a maximum of four times.

\section{Results}

Thematic analysis of content (Bos \& Tarnai, 1999) with predefined axes was considered as the most appropriate method for such an investigation. The analysis was held in the NVivo 10 software for qualitative data analysis. The predefined axes were in correspondence with the research questions. Specifically, they were:

(a) Themes;

(b) Time sequence and repeatability;

(c) Selection criteria of themes;

(d) Content of educational activities: Learning area, activities, educational material, and space of classroom;

(e) Teaching methods.

\section{Themes}

Thematic analysis revealed that the vast majority of the reported activities were developed in the context of a specific theme. More specifically, during the academic year 2012-2013, the activities that were designed under a specific theme reached $89.5 \%$. Similarly, the same level was achieved during the next year 2013-2014 with $87.1 \%$.

The themes that kindergarten teachers chose more frequently were "Olive tree," "autumn/fall," "restoration of democracy," and "sowing (bread)" (see Table 1). Such themes were themes-umbrellas which were separated in several sub-themes that were developed around the central theme or were connected with relative themes, causing confusion to small children as these connections are usually more associative than real. For instance, the theme "autumn/fall" included the phenomenon of rain, the circle of water, as well as seasonal fruits. In addition, the theme "Olive tree" was usually connected to "Olive oil" and the Olympic Games. Moreover, teachers tended to connect the "sowing" theme with autumn, as it is a process that takes part during this specific period. They also considered the "sowing" theme to be inextricably bounded with the production of bread. 
Table 1

Frequency of References of Kindergarten Teachers' Theme Preferences

\begin{tabular}{ll}
\hline Themes & References $(N)$ \\
\hline Olive tree & 48 \\
Autumn/fall & 24 \\
Restoration of democracy & 22 \\
Sowing (Bread) & 13 \\
Nutrition & 7 \\
Human body & 6 \\
Weather & 6 \\
Animals & 6 \\
My family & 4 \\
Colors & 4 \\
Sound (Music) & 3 \\
My house & 2 \\
The city of Volos & 2 \\
Traffic behavior & 2 \\
Means of communication & 2 \\
Volcano & 2 \\
Christmas & 2 \\
Plants & 1 \\
Recycling & 1 \\
Our neighborhood & 1 \\
\hline
\end{tabular}

As already mentioned, themes were developed outside of a framework and were concerned during the instruction as isolated concepts, usually related to mathematics. However, such activities were quite rare (see Table 2).

Table 2

Frequency of References of Kindergarten Teachers' Preferences on Isolated Concepts

\begin{tabular}{ll}
\hline Themes (concepts) & References \\
\hline Shapes & 7 \\
Numbers & 3 \\
Fairytale reading & 3 \\
The alphabet & 1 \\
Puppet theatre & 1 \\
\hline
\end{tabular}

\section{Time Sequence and Repeatability}

Data analysis indicated that a respectful percentage of teachers (38.6\%) existed who repeated the themes they developed either within the same academic year or during the next one. According to Table 3, the themes are repeated: (a) once every year; (b) twice in the same academic year; and (c) twice in the same academic year and once in the following year.

Regarding the chosen theme, more than half of the schools (57.1\%) repeated the "Olive tree" theme. Moreover, the repetitions, regardless of the theme, usually occurred once every academic year (57.1\%). 
Table 3

Time Sequence and Repeatability Frequencies of References

\begin{tabular}{|c|c|c|c|c|c|}
\hline \multicolumn{2}{|l|}{ Once every year } & \multicolumn{2}{|c|}{ Twice in the same year } & \multicolumn{2}{|c|}{ Twice in the same year and once in the following } \\
\hline Themes & Schools & Themes & Schools & Themes & Schools \\
\hline Olive tree & 9 & Olive tree & 2 & Olive tree & 1 \\
\hline My family & 1 & Weather & 1 & Sowing & 1 \\
\hline Restoration of democracy & 1 & Means of communication & 1 & Autumn/fall & 1 \\
\hline Autumn/Fall & 1 & Volcano & 1 & - & - \\
\hline- & - & Autumn/fall & 1 & - & - \\
\hline- & - & Shapes & 1 & - & - \\
\hline Total & 12 & Total & 7 & Total & 3 \\
\hline
\end{tabular}

\section{Selection Criteria of Themes}

Kindergarten teachers were interviewed on the selection criteria of themes and their responses were recorded by the observers. Thematic analysis revealed that teachers select the themes based on the timeliness (54 references), due to their perceived significance (21 references), because they were assumed to be interesting for students (18 references), and finally because they believed that those themes correspond to young children's needs ( 7 references).

On a second level of analysis, the selection criteria were compared with the themes. The intersection between those codes showed that for the theme of "restoration of democracy," the exclusive criterion was timeliness $(90.9 \%)$, as the date of observation coincided with the national celebration. According to the observations, the "restoration of democracy" took place at least three days before the national celebration, as $90.5 \%$ of the teachers were observed to develop related activities since 14th of November 2012 (with the celebration day being the 17th of November), while similar activities were observed at least three days after the celebration (i.e., 19th of November), although in fewer cases (9.5\%).

Concerning the "Olive tree" theme, the selection criteria were: timeliness $(72.2 \%)$, because it was the time of Olive harvesting, children's interests (37.5\%), as well as the considered significance of the theme by teachers (11.1\%). Furthermore, the selection of the themes "autumn/fall" and "sowing (bread)" was based on current affairs criteria, student's interests, and significance of the theme. However, some themes were selected solely according to their significance for kindergartens learning, namely, teaching numbers and shapes.

\section{Content of Educational Activities}

The analysis of the specific content focused on the activities that were developed in the context of the most frequent themes ("Olive tree," "autumn/fall," "restoration of democracy," and "sowing (bread)"), in order to deeply analyze teachers' designs and practices.

Since the term content is quite abstract, we created four sub-codes in order to organize our analysis. The sub-codes were the following: (a) learning area, i.e., language, mathematics, studies of the environment, physical education, etc.; (b) activities that were observed, such as painting, completion of a worksheet, etc.; (c) educational material that was used as learning aid of instruction (e.g., pictures, videos, etc.); and (d) space of the classroom, where the activities conducted. In the following subsections, we further analyze the four sub-codes that we used.

Learning area. Significant similarities can be noticed in the manner that different kindergarten teachers developed the theme "Olive tree." Specifically, the teaching goals, and thus, the activities that were observed 
were mainly related to the learning areas of studies of the environment ${ }^{1}(82.6 \%)$, language $(58.7 \%)$, and creation and expression (fine arts) (45.6\%) (see Table 4).

The same picture can be also noticed during the instruction of other popular themes. Namely, during the theme "autumn/fall," kindergarten teachers presented instructional activities mostly related to the studies of the environment (83.3\%) and creation and expression (fine arts) (58.3\%). Similarly, during the theme "restoration of democracy," the goals and the activities were all related to the studies of the environment (100\%), creation and expression (fine arts) (71.4\%), and language (52.4\%). Lastly, during the theme "sowing (bread)," the most referenced learning areas were once more studies of the environment $(92.3 \%)$ and language (58.3\%).

On the other hand, we observed that some cognitive areas were surprisingly marginalized in each and every theme. Hence, the less often referenced goals and activities were from the learning areas of mathematics and creation and expression (music), whereas no references were observed related other cognitive areas from the National Curriculum of Greece, such as Computer Science and Child and Physical Education.

Table 4

Frequency of References of Learning Areas That Were Developed During the Most Popular Themes

\begin{tabular}{llc}
\hline Themes & Learning areas & References \\
\hline & Studies of the environment & 38 \\
& Language & 27 \\
Creation and expression (fine arts) & 21 & 7 \\
Olive tree & Mathematics & 6 \\
& Creation and expression (drama) & 1 \\
& Computer science & 20 \\
\hline & Study of the environment & 14 \\
Creation and expression (fine arts) & 9 \\
& Language & 7 \\
& Creation and expression (drama) & 3 \\
\hline Matumn/fall & Study of the environment & 21 \\
& Creation and expression (fine arts) & 15 \\
Lestoration of democracy & Creation and expression (drama) & 11 \\
& Mathematics & 8 \\
& Creation and expression (music) & 5 \\
Sowing (Bread) & Study of the environment & 3 \\
\hline
\end{tabular}

Activities. Significant similarities in the specific activities existed in every theme that teachers presented in different classrooms. One of the most referenced activities was the conversation with the whole class (see Table 5), where the actual "lesson" was taught. The whole class sat opposite to the teacher as he/she was lecturing and/or asking questions that were usually close-ended. That kind of activity occupied most of the time

\footnotetext{
${ }^{1}$ Learning areas as mentioned in the National Curriculum of Greece (2003), since the implementation of the proposed curriculum of 2011 is not obligatory yet.
} 
used for instruction. Conversation with the whole class was considered as an integral part of the theme development, as it was always the beginning activity that set the cornerstone for the upcoming activities.

Table 5

Frequency of References of Specific Activities Developed in the Frame of the Most Popular Themes

\begin{tabular}{|c|c|c|}
\hline Themes & Activities & References \\
\hline \multirow{11}{*}{ Olive tree } & Language activities & 49 \\
\hline & Conversation (whole class) & 42 \\
\hline & Art activities & 18 \\
\hline & Worksheet (order of oil production) & 9 \\
\hline & Experiment (solubility of oil) & 9 \\
\hline & Cooking & 7 \\
\hline & Wreath of olive branches (Kotinos) & 5 \\
\hline & Dramatization of Olive harvest & 4 \\
\hline & Count of related items & 3 \\
\hline & Classification of deciduous and evergreen trees & 3 \\
\hline & Visit (museum, Olive press) & 3 \\
\hline \multirow{9}{*}{ Autumn/fall } & Conversation (whole class) & 24 \\
\hline & Language activities & 18 \\
\hline & Art activities & 14 \\
\hline & Experiments (about water) & 11 \\
\hline & Dramatization & 7 \\
\hline & Worksheet (circle of water) & 6 \\
\hline & Video (circle of water) & 4 \\
\hline & Singing songs of rain & 3 \\
\hline & Cooking & 2 \\
\hline \multirow{6}{*}{ Restoration of democracy } & Conversation (whole class) & 24 \\
\hline & Language activities & 20 \\
\hline & Art activities & 19 \\
\hline & Dramatization & 8 \\
\hline & Singing songs & 6 \\
\hline & Video (excerpts of historical films) & 1 \\
\hline \multirow{11}{*}{ Sowing (Bread) } & Language activities & 13 \\
\hline & Conversation (whole class) & 10 \\
\hline & Art activities & 6 \\
\hline & Cooking & 2 \\
\hline & Dramatization & 2 \\
\hline & Singing songs & 2 \\
\hline & Planting seeds & 2 \\
\hline & Worksheet (order of bread production) & 1 \\
\hline & Classification of seeds & 1 \\
\hline & Count seeds & 1 \\
\hline & Interview an expert & 1 \\
\hline
\end{tabular}

Regarding the "Olive tree" theme, the conversation was around the subthemes of Olive products (15 references), harvest of Olives (14 references), and oil and its properties ( 8 references). Accordingly, during the theme "autumn/fall," teachers talked about fruits of autumn (4 references), the water circle (11 references), autumn's weather (6 references), and rivers (3 references). Accordingly, the conversation during the "restoration of democracy" theme concerned the narration of historical facts (15 references), as well as the concepts of 
democracy and dictatorship (9 references). Moreover, the same activity during the "sowing (bread)" theme was related to the bread production process ( 4 references), sowing in the past (4 references), and seeds (2 references).

Another highly referenced practice of kindergarten teachers, regardless of the theme, was language activities that usually concerned both learning letters or/and words and narration of myths, tales, and proverbs. More specifically, during the "Olive tree" theme instruction, teachers required from children to create compound words using the words "Olive" or "oil" (11 references), learn to write and read them (6 references), and learn the first letter from the word "Olive" (in Greek) (7 references). Furthermore, they presented the myth of goddess Athena who gave her name to the Greek City of Athens (where the Olive tree was used as a symbol) (10 references), the story of Noah's Ark (as a dove brought back a branch of Olive tree to sign the end of cataclysm) (3 references), reading of related riddles and proverbs (6 references), as well as reading other related tales (6 references).

During the "autumn/fall" theme, children were taught related words ( 6 references), heard the teacher reciting a specific poem about rivers ( 7 references), as well as other associated tales ( 5 references). Reading tales was a frequent activity at the "restoration of democracy," too, as teachers selected a specific tale which addressed the concepts of democracy and dictatorship (14 references), while some writing activities were conducted (write slogans and letters). The same activities occurred at "sowing (bread)," as children wrote names of seeds ( 2 references), learnt related words ( 2 references), riddles and proverbs ( 2 references), and listened to tales ( 7 references).

The analysis showed that teachers preferred quite often to develop art activities, such as constructions (e.g., an Olive tree [ 6 references], about the circle of water [4 references], group collage about democracy [8 references], and constructions with pasta and seeds [2 references]) and paintings (35 references), usually with the use of worksheets (14 references). Those kind of activities occurred after the main learning activities, namely, conversation (with the whole class), since they were considered as consolidating activities.

Moreover, other activities that were developed indicated interesting similarities regardless of the theme. For instance, the use of worksheets was pretty dominant in activities that aimed specific procedural processes, like learning the order of oil production ( 9 references), circle of water (6 references), and order of bread production (1 reference). In addition, many teachers developed cooking activities, such as making Olive cookies, fruit salads, and bread. During the cooking activities, as also during the experiments, teachers had the leading role since they demonstrated the process while children had mostly a passive role.

Educational material. The materials that teachers included in their instruction were mainly printed and real objects rather than digital. The printed materials included photographs or/and pictures ( 54 references) (e.g., Olive trees, stages of oil production, stages of circle of water, and historical photographs), various cards with words and letters ( 6 references), and fairy tales and poems (17 references). In addition, the real objects stemmed from the nature ( 31 references) (e.g., branches of Olive tree, leaves, seeds, and fruits), as well as famous paintings (6 references) and puppet dolls ( 2 references). Despite the fact that printed materials and real objects were dominant throughout the activities, regardless of the theme, digital materials were used in a few instances, including mostly music and sound excerpts (16 references) and videos ( 7 references).

Classroom space. The vast majority of activities were conducted inside the classroom (172 references) rather than outdoor ( 5 references). Specifically, most of the teachers preferred to initially gather the children at the conversation area (99 references), where the actual lesson took place, and later moved on the tables (70 
references) for children to practice on the new knowledge they just heard. In some very few cases, during the "sowing (bread)" theme, after or before the gathering time in the conversation area, teachers used the computer area ( 2 references) as well as the science area ( 1 references). Nevertheless, even in these cases, the role of the children remained passive, since the teacher demonstrated a video or some nature objects while children were not encouraged to cooperate with each other or touch the items (computers or nature objects).

\section{Teaching Methods}

According to Table 6, the most occurring method of teaching was conversation (161 references), which in fact included close-ended questions that teachers posed to the children about concepts they had already learnt. The conversation method was mainly accompanied with the questions and answers method (160 references) which did not encourage a viral conversation between the students, but only a limited exchange between teacher and students.

As we have already mentioned, teachers used to lecture (98 references) in front of the children in their attempt to impart the knowledge. As a result, they very rarely organized their class in small groups (22 references) and even when they did, children's work could not be characterized as cooperative. Instead, children were gathered all together at most of the teaching time (171 references).

Table 6

Instances of References of Teaching Methods

\begin{tabular}{lc}
\hline Methods & References \\
\hline Conversation & 161 \\
Questions and answers & 160 \\
Lecture & 98 \\
Picture observation & 82 \\
Fact's description & 52 \\
Narration & 51 \\
Demonstration & 41 \\
Role playing & 35 \\
Experiment & 24 \\
Video projection & 17 \\
Puppet show & 3 \\
Educational visiting & 3 \\
\hline
\end{tabular}

\section{Discussion and Conclusion}

The scope of the present study was the investigation of the instructional content that occurs in kindergarten, i.e., the applied educational practices and the exact instructional content that is taught. The analysis of data showed that there were interesting similarities between teachers' practices. Such findings are allied with the previous research of Kakana (2011), as we initially hypothesized.

More specifically, our findings indicated that there was a specific model of educational practice which teachers tend to apply, regardless of the theme they developed. According to this model, instruction always started with a "conversation," that was actually a lecture from the teacher who introduces the theme and imparts the knowledge he/she considers significant. The second stage of the model included individual assignments to the students aiming to consolidate the new knowledge through worksheets or various construction activities. Every other activity that teachers developed was usually adjusted in this model of practice. 
Moreover, the art activities that occurred during the consolidation stage were mainly applied in order to fill any possible time gap rather than addressing educational goals. Combining the way they used arts with the fact that the theme "restoration of democracy" was developed in three days before and after the national celebration, highlights the lack of organization of time, as well as the lack of intention to experiment with different themes. Consequently, teachers seemed not to be well-prepared and thus they extended every situation, i.e., celebration day, to fill the teaching time.

The above results suggest that kindergarten teachers maintained a conservative approach towards learning and teaching, since they preserved an agenda with pre-designed themes and activities which were applied in the exact same way every year. Therefore, they seemed to be unwilling in updating any of their teaching design or adapting them according to the students' needs. Possibly, such conservatism stems from their insecurity to experiment with approaches they may not be trained and subsequently feel unprepared (Kakana, Ioannidis, \& Kotzampasaki, 2004). The selected themes, the activities, and the educational material indicate the intense didacticism of teachers who are trying to lead children in the one and only correct answer. Their obvious focus on direct teaching highlights the dominance of the model of knowledge transfer. Therefore, Greek teachers seem to be baffled to make the transition into a more developmentally appropriate program that is also suggested by the formal curriculum for early childhood education (Kakana, 2011; Kalantzis \& Cope, 2012; Lave \& Wenger, 1992).

In addition, they emphasize and consider critical for children to learn specific knowledge skills, which becomes obvious from their options during the development of themes, while on the other hand they ignore other cognitive areas. More specifically, they focus on the language instruction, as well as on the children's engagement with crafts, while they avoid activities related to new technologies, mathematics, and music education. The teacher deviation from designing activities related to new technologies strengthens the point that they are quite unfamiliar with them, and especially with the potential to utilize them into their educational practice (Tsitouridou \& Vryzas, 2004; Saúdea, Cariocaa, Siraj-Blatchfordb, Sheridanc, Genovd, \& Nueze, 2005).

Additionally, they considered that mathematics could not be easily included in themes and as a result they tended to teach them separately. Concerning the music education, teachers avoided to engage children in producing their own music or play with instruments, as it turns the classroom into a noisy environment. The complete omission of the physical education could be reflected into the following principles:

1. The established opinion that children should stay seated in the classroom during the "lesson";

2. Children can only move or play during the break or/and during the free activities;

3. Based on 1 and 2, at the same time, they prepare themselves for the rules of elementary school.

Apparently, the teaching practice did not promote the holistic development of the children or any creativity skills, as the formal curriculum of Greece (Hellenic Ministry of Education and Religious Affairs, 2003) suggests. Although this curriculum is aligned with developmentally appropriate practices, its implementation seems to puzzle teachers, as their everyday practices, including the themes, the way they develop them and the instructional activities are mainly knowledge-centered and old-fashioned (Kakana, 2011). The lack of holistic development from everyday practice in kindergarten illustrates the low quality of the educational content (Feeney \& Moravcik, 2005; Logue, 2007).

Generally, it was observed that the most experiential activities, which are characterized as developmentally appropriate, occurred less often, indicating the teacher-centered approach of instruction, as students remained passive. As a matter of fact, current learning situations in kindergarten are stuck in principles 
and methods of the 19th century, since memorization of distributed knowledge and treatment of children as blank papers are still on the core of teachers' practice (Koutsouri, 2007).

According to our results, teachers argued that children were interested in the "Olive tree" theme and that it emerged from them. However, that was actually an assumption that they made in order to provide a developmentally appropriate explanation. Former findings highlighted the tendency that teachers have to promote a more developmentally appropriate approach than their actual practice demonstrates (Charlesworth et al., 1991; National Association for the Education of Young Children [NAYEC], 2003; Spodek, 1999; Rentzou \& Sakellariou, 2011).

However, there is a restriction that should be taken into consideration as it may have affected the results of the study. Teachers were aware of being recorded and thus they may have altered their behavior. Nevertheless, such a restriction was attempted to be limited. Although the observers recorded all the activities that occurred that day, only one activity from each classroom was used as our data input while teachers did not know which one was actually used. Additionally, although teachers were aware of the study, they did not have access to its precise goals in order to accordingly alter their behavior and practice.

Concluding, the present study delineated the significant gap that exists between the formal suggestions and the teaching practice in kindergartens. Teachers seemed to be quite conservative with their instructional approaches. Therefore, significant consideration arises, on one hand, about the deeper reasons that determine their preferences, and on the other hand, concerning the type of interventions that may lead to update their practice and approaches.

As we mentioned, numerous studies emphasize that each teacher owns a personal theory and a personal history. Thus, our results should be taken into account when developing, organizing, and implementing in-service training programs are planned (Dunn \& Dunn, 1979; MacNeil, 1980; Meyers \& Myers, 1980). The absence of any active, self-involving procedure in the course of a teacher's professional development seems to turn training into a simply academic, unreliable, and ineffective process (Bagakis, Demertzi, \& Stamatis, 2007; Dakopoylou, 2000; Kakana et al., 2004; Riga \& Botsoglou, 2004; Vergidis, 1995).

The initial focus should be on teacher training programs as it is urgent to facilitate teachers with adaptive expertise in order to be more effective and innovative. Such teachers would be able to apply appropriate practices and teaching approaches, as also to interlard established practices, evaluate and reflect their actions, in order to improve their teaching skills (Hammerness, Darling-Hammond, \& Bransford, 2005).

Consequently, the development of adaptive expertise presupposes the cultivation of analyzing and reflecting skills of teaching and learning and more importantly on their own educational practice (Feiman-Nemser, 1990; Schön, 1983; Zeichner \& Liston, 1996). Hence, the question is what kind of teachers' training procedures could contribute in the configuration of reflective teachers who are able to link flexibly theory and practice and choose accordingly the instructional approach. All in all, further investigation on content and instructional approaches that define the educational context in kindergarten adds significant value to the deeper understanding of kindergarten practice.

\section{References}

Allen, G. (2011). Early intervention, the next steps (An independent report to Her Majesty's Government, the Stationery Office). Bagakis, G., Demertzi, K., \& Stamatis, Th. (Eds.) (2007). A school learns: Self-evaluation of a school under the program Carpe Vitam: Leadership for learning. Athens: Livani. 
Bodovski, K., \& Farkas, G. (2007). Do instructional practices contribute to inequality in achievement? The case of mathematics instruction in kindergarten. Journal of Early Childhood Research, 5, 301-322.

Bos, W., \& Tarnai, C. (1999). Content analysis in empirical social research. International Journal of Educational Research, 31(8), 659-671.

Charlesworth, R., Hart, C. H., Burts, D. C., \& Hernandez, S. (1991). Kindergarten teachers' beliefs and practices. Early Child Development and Care, 70(1), 17-35.

Claessens, A., Engel, M., \& Curran, F. C. (2014). Academic content, student learning, and the persistence of preschool effects. American Educational Research Journal, 51(2), 403-434.

Dakopoylou, A. (2003). Training of Greek primary education teacher's: Teacher's perceptions, experiences and preferences. Retrieved from http://www.pee.gr/e27_11_03/sin_ath/mer_c_th_en_iii/dakopoyloy.htm

Dunn, R. S., \& Dunn, K. J. (1979). Learning styles/teaching styles: Should they ... can they ... be matched? Educational Leadership, 36, 238-244.

Engel, M., Claessens, A., \& Finch, M. (2013). Teaching students what they already know? The misalignment between instructional content in mathematics and student knowledge in kindergarten. Educational Evaluation and Policy Administration, 35, 157-178.

Feeney, S., \& Moravcik, E. (2005). What should they be learning in preschool? The development of preschool content standards in Hawaii. Educational Perspectives, 38(1), 27-31.

Feiman-Nemser, S. (1990). Teacher preparation: Structural and conceptual alternatives. In W. R. Houston (Ed.), Handbook of research on teacher education (pp. 212-229). New York, N.Y.: McMillan.

Flouris, G. (1995). Curricula for a new age of education. Athens: Gregory.

Giardiello, P., McNulty, J., \& Anderson, B. (2013). Observation, assessment and planning practices in a children's centre. Child Care in Practice, 19(2), 118-137.

Hammerness, K., Darling-Hammond, L., \& Bransford, J. (2005). How teachers learn and develop. In L. Darling-Hammond, \& J. Bransford (Eds.), Preparing teachers for a changing world: What teachers should learn and be able to do. San Francisco, C.A.: Wiley \& Sons.

Hatch, J. A., \& Freeman, E. B. (1988). Kindergarten philosophies and practices: Perspectives of teachers, principals, and supervisors. Early Childhood Research Quarterly, 3(2), 151-166.

Hellenic Ministry of Education and Religious Affairs. (2003). Cross-thematic curriculum framework for nursery school. Athens: Hellenic Ministry of Education and Religious Affairs.

Kakana, D. M. (2011). Thematic approaches in preschool education: Creative actions or stereotypic options? In S. Nektarios, \& M. Efstathiadou (Eds.), European regional conference: Perspectives of creativity and learning in early childhood. Cyprus: Cypriot Committee of OMEP.

Kakana, D., Ioannidis, X., \& Kotzampasaki, E. (2004). A successful training program: Afterwards what? Teachers' opinions about continuing support of their work. Teaching of natural sciences. Research and Act, 10, 20-26. (In Greek)

Kalantzis, M., \& Cope, B. (2012). Didactic. Retrieved from http://newlearningonline.com/learning-by-design/glossary/didactic/

Kallestad, J. H., \& Ødegaard, E. E. (2013). Children's activities in Norwegian kindergartens (Part 1: An overall picture). Cultural-Historical Psychology, 4, 74-81.

Koutsouri, A. (2007). Instructional methodology: Creative activities and learning processes. Athens: Hellenic Ministry of Education and Religious Affairs.

Lave, J., \& Wenger, E. (1992). Situated learning: Legitimate peripheral participation. Cambridge, U.K.: Cambridge University Press.

Leung, C. (2012). Teacher beliefs and practices of kindergarten teachers in Hong Kong. Australasian Journal of Early Childhood, $37(1), 38-54$.

Logue, M. E. (2007). Early childhood learning standards: Tools for promoting social and academic success in kindergarten. Children \& Schools, 29(1), 35-43.

MacNeil, R. (1980). The relationship of cognitive style and instructional style to the learning performance of undergraduate students. Journal of Educational Research, 22, 354-359.

Melhuish, E. C. (2011). Preschool matters. Science, 333(6040), 299-300.

Meyers, I. B., \& Myers, P. B. (1980). Gifts differing. Palo Alto, C.A.: Consulting Psychologists Press.

National Association for the Education of Young Children (NAYEC). (2003). Early childhood curriculum, assessment and program evaluation: Building an effective, accountable system in programs for children birth to age 8 (Position Statement). Washington, D.C.: Author. 
New, R. S. (1999). What should children learn? Making choices and taking chances. Early Childhood Research and Practice, 1(2). Retrieved from http://ecrp.uiuc.edu/v1n2/new.html

Ntoliopoulou, E. (2005). Current curricula for kindergarten children. Athens: Typotheto.

Organization for Economic Co-operation and Development (OECD). (2001). Starting strong: early childhood education and care. Paris: Author.

OECD. (2003). Five curriculum outlines. Paris: Author.

OECD Reports. (2004). Background Reports (prepared by country) and Country Notes (written by OECD experts teams) have been prepared for Austria, Canada, France, Germany, Hungary, Ireland, Korea and Mexico. These reports are available at hhtp://www.oedc.org/edu/earlychildhood

Rentzou, K., \& Sakellariou, M. (2011). Greek pre-service kindergarten teachers' beliefs about and practices of developmentally appropriate practices in early childhood education. Early Child Development and Care, 181(8), 1047-1061.

Riga, V., \& Botsoglou, K. (2004). Reforming "traditional" teaching methods in in-service training programs for early childhood teachers: An action research project. International Journal of Learning, 11, 223-230.

Saúdea, S., Cariocaa, V., Siraj-Blatchfordb, J., Sheridanc, S., Genovd, K., \& Nueze, R. (2005). KINDERET: Developing training for early childhood educators in information and communications technology (ICT) in Bulgaria, England, Portugal, Spain and Sweden. International Journal of Early Years Education, 13(3), 265-287.

Schön, D. A. (1983). Educating the reflective practitioner. San Francisco, C.A.: Jossey-Bass.

Spodek, B. (1988). The implicit theories of early childhood teachers. Early Child Development and Care, 38(1), 13-32.

Tickell, C. (2011). The early years: Foundations for life, health and learning (An independent report on the early years foundation stage to Her Majesty's Government).

Tsitouridou, M., \& Vryzas, K. (2004). The prospect of integrating ICT into the education of young children: The views of Greek early childhood teachers. European Journal of Teacher Education, 27(1), 29-45.

Vergidis, D. (1995). From the faculties of training in the regional training centers: Critical review of teacher's training. In A. Kazamias, \& M. Kassotakis (Eds.), Greek education: Prospects of reconstruction and modernization. Athens: Seirios.

Vygotsky, L. S. (1978). Mind in society. (S. Vosniadou, Trans.). Athens: Gutenberg.

Zeichner, K., \& Liston, D. (1996). Reflective teaching: An introduction. Mahwah, N.J.: Lawrence Erlbaum Associates. 